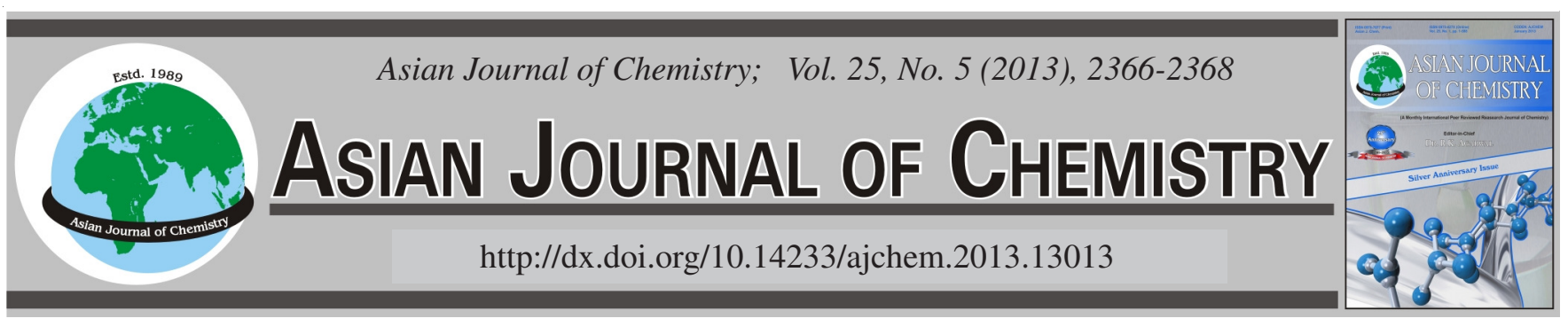

\title{
Synthesis, Characterization and Evaluation of Topical Antiinflammatory Activity of Dimethyl 4-Oxo-2,6-diphenylcyclohexane-1,1-dicarboxylate
}

\author{
Mazin Nadhim Mousa Al Ugla
}

Department of Pharmaceutical Chemistry and Pharmacognosy, College of Pharmacy, University of Basrah, Basrah, Iraq

Corresponding author: E-mail: malugla@yahoo.com

(Received: 4 November 2011;

Accepted: 5 November 2012)

AJC-12361

\begin{abstract}
An attempt was made to synthesize a topical preparation of an active compound that has a potent antiinflammatory activity. Dimethyl 4oxo-2,6-diphenylcyclohexane-1,1-dicarboxylate (II) was prepared by aldol condensation of benzaldehyde and acetone followed by Michael addition of dimethyl malonate. The optimum concentration of the compound was determined by comparing the antiinflammatory effect of ointment preparations at different concentrations. The antiinflammatory effects were studied by using carrageenan-induced paw edema method in rat and xylene induced rat ear edema. Good effect was observed with ointment containing $4 \%$ and $5 \%$ of the compound II concentration. The results showed that the drug had an obvious antiinflammatory effect as an external preparation and the activity is comparable to that of the standard ointment.
\end{abstract}

Key Words: Antiinflammatory, Carrageenan-induced edema, Xylene induced edema.

\section{INTRODUCTION}

Inflammation is a localized protective response characterized by injury or destruction of tissues, which serve to destroy, dilute or sequester both the injurious agent and injured tissue.

Antiinflammatory agents are used in the treatment of inflammation. There are two main types of antiinflammatory agents; glucocorticosteroids and non-steroidal antiinflammatory drugs. The non-steroidal antiinflammatory drugs is so named because they do not belong to the steroidal groups and ceases discomfort by blocking the pathway of cyclo-oxygenase enzyme that creates prostaglandins and lessen the pain in different parts of the body. While the steroids reduces the inflammation by binding to cortisol receptors.

Many therapeutic agents from synthetic source have advantages and disadvantages, which limits their usefulness on long term basis. Similarly, non-steroidal antiinflammatory drugs also show many side effects includes stomach ulcers, bleeding ulcers, kidney dysfunction, constipation, dizziness and headaches ${ }^{1}$. Thus, the application of the drug on the affected site or the nearby area is reasonable, since drugs produce effects after they reach the affected site. Topical nonsteroidal anti inflammatory drugs are applied on the skin in the form of ointment, gel, cream or spray in the region where pain is exist ${ }^{2}$. They have to penetrate the skin, enter tissues or joints and at high concentration to have an effect on the inflammation process causing pain. The inhibitory activities of non-steroidal antiinflammatory drug ointment on inflammatory responses were almost the same as those obtained by oral administration of such non-steroidal antiinflammatory drug and more potent than those of steroidal ointment ${ }^{3}$. So, the aim of this study is to develop a compound that have antiinflammatory effect, applied topically to reduce the side effects.

\section{EXPERIMENTAL}

Synthesis of (1E, 4E)-1,5-diphenylpenta-1.4-dien-3-one (I): In a $100 \mathrm{~mL}$ beaker, place $10 \mathrm{~mL}$ of $3 \mathrm{M}$ sodium hydroxide solution, $16 \mathrm{~mL}$ of $95 \%$ ethanol and $2.12 \mathrm{~g}(20 \mathrm{mmol})$ of benzaldehyde, then add $0.58 \mathrm{~g}(10 \mathrm{mmol})$ of acetone to the reaction mixture and shake the mixture. The benzaldehyde, initially insoluble, goes into solution, resulting in a clear, paleyellow solution. After a minute it suddenly becomes cloudy and a yellow precipitate product forms. Continue to shake the beaker for the next $10 \mathrm{~min}$. Remove the liquid from the beaker and add $30 \mathrm{~mL}$ of water and shake it vigorously. Remove the wash liquid and wash the crystals twice with 20 -mL portions of water and then filtration by vacuum, drying and recrystallized from hot ethanol. The yield was $c a .78 \%$ and the melting point was $111-112^{\circ} \mathrm{C} .^{4}$

IR (KBr, $v_{\max }, \mathrm{cm}^{-1}$ ): 3051.1 ( Ar. C-H stretching), 3029.9 (C-H stretching), 1649 (C=O stretching), 1591, 1496 (Ar. C=C stretching), 883 (Ar. C-H out of plane). 


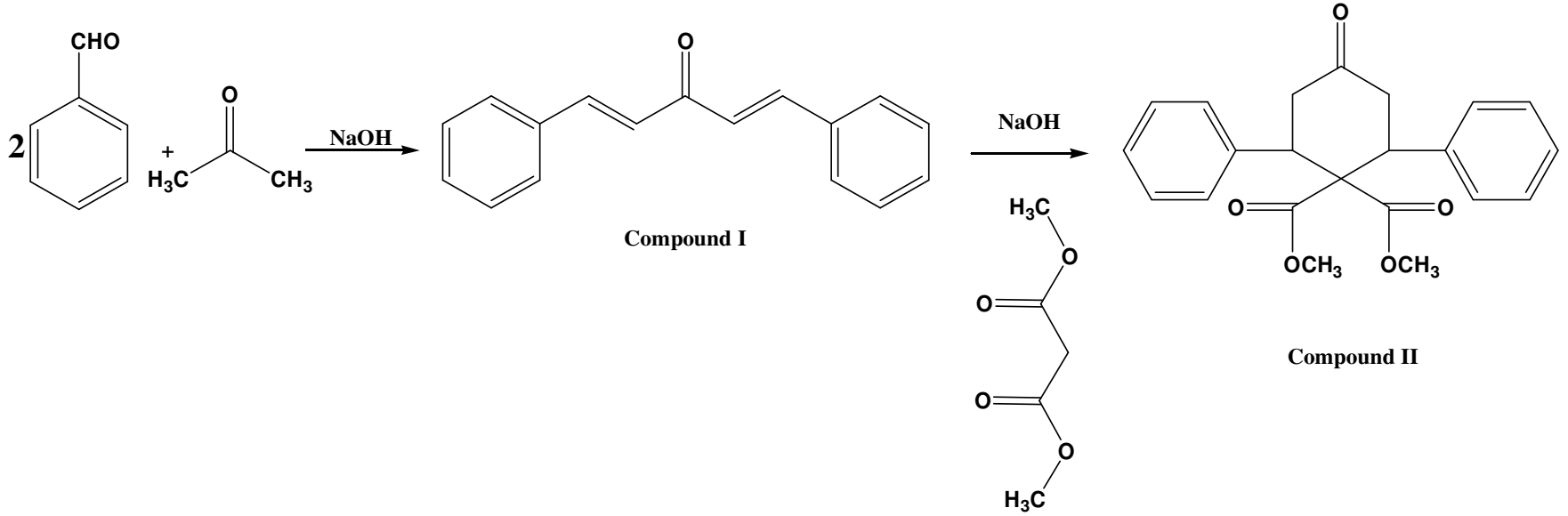

TABLE-2

EFFECT OF TOPICAL APPLICATION OF THE FORMULATION ON CARRAGEENAN INDUCED PAW EDEMA IN RATS

\begin{tabular}{|c|c|c|c|c|c|c|c|c|}
\hline \multirow{2}{*}{ Compound } & \multicolumn{4}{|c|}{ Change in paw volume (in $\mathrm{mL}$ ) after drug administration (Mean \pm SEM) } & \multicolumn{4}{|c|}{ Percentage inhibition of edema } \\
\hline & $1 \mathrm{~h}$ & $2 \mathrm{~h}$ & $3 \mathrm{~h}$ & $4 \mathrm{~h}$ & $1 \mathrm{~h}$ & $2 \mathrm{~h}$ & $3 \mathrm{~h}$ & $4 \mathrm{~h}$ \\
\hline Control & $0.71 \pm 0.02$ & $0.77 \pm 002$ & $0.71 \pm 0.02$ & $0.60 \pm 0.02$ & - & - & - & - \\
\hline Standard & $0.42 \pm 0.03^{* *}$ & $0.43 \pm 0.04 * *$ & $0.44 \pm 0.04 * *$ & $0.40 \pm 0.03 * *$ & 40 & 44 & 38 & 33 \\
\hline $\mathrm{F} 1$ & $0.58 \pm 0.04$ & $0.60 \pm 0.01$ & $0.57 \pm 0.05$ & $0.49 \pm 0.03$ & 19 & 22 & 21 & 19 \\
\hline $\mathrm{F} 2$ & $0.54 \pm 0.02 *$ & $0.57 \pm 0.01 *$ & $0.53 \pm 0.04$ & $0.48 \pm 0.04$ & 24 & 26 & 26 & 20 \\
\hline $\mathrm{F} 3$ & $0.52 \pm 0.01 *$ & $0.55 \pm 0.01 *$ & $0.51 \pm 0.04 *$ & $0.48 \pm 0.04$ & 27 & 28 & 29 & 20 \\
\hline $\mathrm{F} 4$ & $0.49 \pm 0.02 * *$ & $0.53 \pm 0.02^{* *}$ & $0.48 \pm 0.04 * *$ & $0.47 \pm 0.04$ & 30 & 31 & 33 & 22 \\
\hline F5 & $0.47 \pm 0.04 * *$ & $0.50 \pm 0.04 * *$ & $0.47 \pm 0.04 * *$ & $0.46 \pm 0.04$ & 34 & 35 & 34 & 24 \\
\hline
\end{tabular}

SEM- Standard error mean, $* \mathrm{P}<0.05 ; * * \mathrm{P}<0.01$

Synthesis of dimethyl 4-oxo-2,6-diphenylcyclohexane1,1-dicarboxylate (II): Dissolve $1 \mathrm{~g}(4.46 \mathrm{mmol})$ of compound I in methanol, to which add dimethyl malonate $0.6 \mathrm{~g}$ (4.5 $\mathrm{mmol}$ ) and $3 \mathrm{~mL} 25 \%$ sodium hydroxide solution and reflux for $5 \mathrm{~min}$, then left for it over night, cool and collect the product by vacuum filtration and recrystallized from ethanol and water. The yield was about $81 \%$ and the melting point was $292-295^{\circ} \mathrm{C}$.

IR (KBr, $\boldsymbol{v}_{\max } \mathbf{~ c m}^{-1}$ ): 3047 ( Ar. C-H stretching), 2873 (C-H stretching $\mathrm{CH}_{3}$ ), $2851\left(\mathrm{C}-\mathrm{H}\right.$ stretching $\left.\mathrm{CH}_{2}\right) 1735$ (ester $\mathrm{C}=\mathrm{O}$ ), 1672 (keton $\mathrm{C}=\mathrm{O}$ ), 1587, 1501 (Ar. $\mathrm{C}=\mathrm{C}$ stretching), 1370 (C-H bending $\mathrm{CH}_{3}$ ), 1105 (C-O stretching), 879 (Ar. C$\mathrm{H}$ out of plane).

${ }^{1}$ H NMR (DMSO): $\delta 7.39(4 \mathrm{H}), \delta 7.31(4 \mathrm{H}), \delta 7.26(2 \mathrm{H})$, $\delta 4,34(2 \mathrm{H}), \delta 3.66(6 \mathrm{H}), \delta 2,61(42 \mathrm{H}), \mathrm{C}_{22} \mathrm{H}_{22} \mathrm{O}_{5}$ (m.w. 366): Elemental analysis (\%) (Calcd.) C, 72.12; H, 6.05; (Found) C, $72.3 ; \mathrm{H}, 6.09$.

Method of preparation of ointment ${ }^{5}$ : Ointment was prepared by melting together petrolatum, polyethylene glycol3000 , propylene glycol and menthol on a hot plate $\left(70^{\circ} \mathrm{C}\right)$. The compound II was dissolved in it under stirring and cooled. Various compositions of ointment formulations were mentioned in the Table-1.

\section{Antiinflammatory activity}

Carrageenan-induced rat paw edema: Antiinflammatory activity was carried out using carrageenan-induced rat paw edema $^{6}$. The rats weighing between 150-200 g were selected randomly excluding pregnant female rats for the test. Animals were divided into different groups with six animals in each group. One group of rats were treated with ointment base which served as control, other group was treated with standard oint- ment $(0.1 \%$ diclofenac sodium in ointment base). Remaining groups were treated with formulated ointment (F1-F5). $0.2 \mathrm{~g}$ of ointment was applied to the plantar surface of the hind paw by gentle rubbing 50 times with index finger. After $30 \mathrm{~min}$, $0.1 \mathrm{~mL}$ of $1 \% \mathrm{w} / \mathrm{v}$ of carrageenan was injected in the plantar region of the left paw of rats. The paw volumes were noted for $1,2,3$ and $4 \mathrm{~h}$ after carrageenan injection. The results were tabulated in Table- 2 . The percentage edema inhibition by the drug was calculated by the formula:

Percentage edema inhibition $=\left[1-\left(\mathrm{V}_{\mathrm{t}} / \mathrm{V}_{\mathrm{c}}\right)\right] \times 100 \%$ where, $\mathrm{V}_{\mathrm{t}}$ : is edema volume in drug treated group. $\mathrm{V}_{\mathrm{c}}$ : is edema volume in the control group.

\begin{tabular}{|c|c|c|c|c|c|}
\hline \multicolumn{6}{|c|}{$\begin{array}{c}\text { TABLE-1 } \\
\text { COMPOSITION USED IN THE STUDY } \\
\text { TO PREPARE THE OINTMENTS }\end{array}$} \\
\hline Ingredients $(\mathrm{g})$ & F1 & $\mathrm{F} 2$ & F3 & F4 & F5 \\
\hline Tested compound & 0.1 & 0.2 & 0.3 & 0.4 & 0.5 \\
\hline Polyethyleneglycol-3000 & 0.6 & 0.6 & 0.6 & 0.6 & 0.6 \\
\hline Propylene glycol & 0.4 & 0.4 & 0.4 & 0.4 & 0.4 \\
\hline Menthol & 0.5 & 0.5 & 0.5 & 0.5 & 0.5 \\
\hline Petroleum & $\begin{array}{l}\text { q.s. } \\
\text { to } 10\end{array}$ & $\begin{array}{l}\text { q.s. } \\
\text { to } 10\end{array}$ & $\begin{array}{l}\text { q.s. } \\
\text { to } 10\end{array}$ & $\begin{array}{l}\text { q.s. } \\
\text { to } 10\end{array}$ & $\begin{array}{l}\text { q.s. } \\
\text { to } 10\end{array}$ \\
\hline
\end{tabular}

Xylene induced rat ear edema: The effect of the product on acute edema was assessed by using xylene induced ear edema in rats as described by Dkhil et al. ${ }^{7}$. The animals were divided into six groups each of six animals. $50 \mu \mathrm{L}$ of xylene was applied to the anterior and posterior surfaces of the two ears under light ether anesthesia. After 15 mins, $0.1 \mathrm{~g}$ of the formulated ointment (F1-F5) were applied on the right ears of five groups, the sixth group receive $0.1 \mathrm{~g}$ diclofenac sodium 
(standard). The left ear was considered as control and receive ointment base only. After $4 \mathrm{~h}$, xylene application rats were sacrificed and both ears were removed. Ear lobes were punched out in circular disc using metal punch ( $6 \mathrm{~mm}$ diameter) and weighed. The difference in the weight of discs from right treated and left untreated was calculated and was used as measure of edema. The results were tabulated in Table- 3 . The level of percentage inhibition was calculated using the formula: Percentage inhibition $(\%)=[($ control-treated $) /$ control $] \times 100 \%$

Statistical analysis: The results were expressed in mean \pm SEM. The data from experiments were analyzed separately using one-way Anova followed by Dunnett test was used to determine significant difference between the groups and $\mathrm{p}<0.05$ was considered significant.

TABLE-3

EFFECT OF TOPICAL APPLICATION OF THE FORMULATION ON XYLENE INDUCED RATS EAR EDMA MODEL

\begin{tabular}{ccc}
\hline Treatment groups & $\begin{array}{c}\text { Ear edema }(\mathrm{mg}) \\
(\text { Mean } \pm \mathrm{SEM})\end{array}$ & Inhibition $(\%)$ \\
\hline Control & $8.33 \pm 0.61$ & - \\
Standard & $3.50 \pm 0.22$ & 57.98 \\
F1 & $7.31 \pm 0.55$ & 12.2 \\
F2 & $6.52 \pm 0.32$ & $21.7^{*}$ \\
F3 & $5.47 \pm 0.37$ & $34.3^{*}$ \\
F4 & $4.13 \pm 0.28$ & $50.4^{* *}$ \\
F5 & $3.95 \pm 0.23$ & $52.6^{* *}$ \\
\hline SEM- Standard error mean, ${ }^{*} \mathrm{P}<0.05 ; * \mathrm{P}<0.01$ &
\end{tabular}

\section{RESULTS AND DISCUSSION}

Statistical analysis showed that, the edema inhibition was significantly different from control group at all the tested concentrations. The results showed that the antiinflammatory effect was more for the formulations containing $4 \%$ and $5 \%$ of the tested compound.

Different formulations (F1-F5) were prepared by keeping the ointment base constant and changing the drug ratio (1$5 \%$ ). All the formulations were stable for evaluation of antiinflammatory activity.

Antiinflammatory activity was carried out for the formulated compounds using carrageenan-induced rat paw edema method and xylene induced rat ear edema.
Carrageenan-induced paw edema in rat and xylene induced rat ear edema has been accepted as a useful phlogistic tool for investigating antiinflammatory agents. It is suggested that there are biphasic effects in carrageenan-induced edema. The early hyperemia results from the release of histamine and serotonin, the delayed phase of carrageenan-induced edema results mainly from the potentiating effects of bradykinin on mediator release and also from prostaglandins which produce edema after the mobilization of leukocytes ${ }^{8}$.

The edema was reached its highest thickness $4 \mathrm{~h}$ after the application of the stimulus ${ }^{9}$.

The compound II promoted a significant and dosedependent inhibition of xylene induced skin inflammation. Topically applied xylene resulted in activation of pro-inflammatory mediators that promoted the manifestation of several inflammatory parameters similar to some skin disorders ${ }^{10}$. Using this model, compounds that inhibit this process can be target in the search for new therapeutic strategies.

\section{Conclusion}

From this result, it is concluded that topical preparation containing $5 \%$ possesses good antiinflammatory activity which can be used for the treatment of topical inflammation.

\section{REFERENCES}

1. International Journal of PharmTech Research, Evaluation of Antiinflammatory Activity and Potency of Herbal Formulation Consists of Different Proportions of Curcuma longa and Boswellia serrata by Using Cotton Pellet granuloma and Xylene Induced Mice Ear Edema Model, vol. 2, no.3, pp. 1855-1860, July-Sept (2010).

2. K. Kyuki, Nippon Yakurigaku Zasshi, 79, 461 (1982).

3. J.H. Vaile and P. Davis, Drugs, 56, 783 (1998).

4. S. Handayani and I.S. Arty, J. Phys. Sci., 19, 61 (2008).

5. D. Giles, R. Karkib, F.R. Sheeba, D.P. Venkatesh and P.M. Gurubasavarajaswamy, J. Pharm. Sci. Res., 3, 1253 (2011).

6. K. Morteza-Semnani, M. Saeedi and M. Hamidian, Fitoterapia, $\mathbf{7 5}$, 123 (2004).

7. M.A. Dkhil, A.S. Abdel-Baki, S. Al-Quraishi and M. Al-Khalifa, Afr. J. Pharm. Pharmacol., 4, 115 (2010).

8. P. Garcia-Pastor, A. Randazzo, L. Gomez-Paloma, M.J. Alcaraz and M. Paya, J. Pharmacol. Exp. Ther, 289, 166 (1999).

9. F. Sharififar, P. Khazaeli and N. Alli, Iran. J. Pharm. Sci., 5, 157 (2009).

10. M. Gabor, Methods Mol. Biol., 225, 129 (2003). 